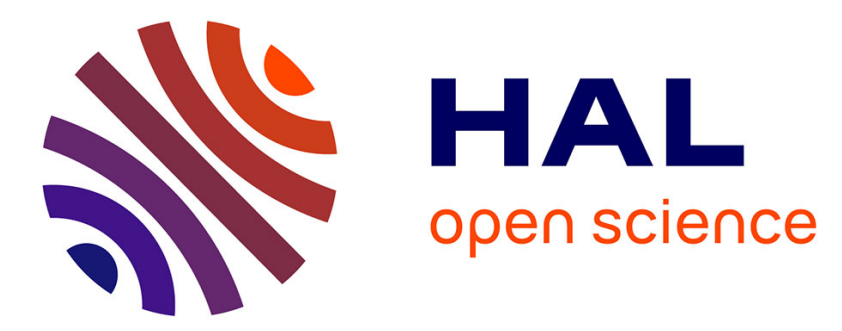

\title{
Sound intensity as a function of sound insulation partition
}

\author{
S. Cvetkovic, R. Prascevic
}

\section{To cite this version:}

S. Cvetkovic, R. Prascevic. Sound intensity as a function of sound insulation partition. Journal de Physique IV Proceedings, 1994, 04 (C5), pp.C5-155-C5-158. 10.1051/jp4:1994528 . jpa-00252971

\section{HAL Id: jpa-00252971 https://hal.science/jpa-00252971}

Submitted on 1 Jan 1994

HAL is a multi-disciplinary open access archive for the deposit and dissemination of scientific research documents, whether they are published or not. The documents may come from teaching and research institutions in France or abroad, or from public or private research centers.
L'archive ouverte pluridisciplinaire HAL, est destinée au dépôt et à la diffusion de documents scientifiques de niveau recherche, publiés ou non, émanant des établissements d'enseignement et de recherche français ou étrangers, des laboratoires publics ou privés. 


\title{
Sound intensity as a function of sound insulation partition
}

\author{
S.D. CVETKOVIC and R.M. PRASCEVIC
}

Faculty of Occupational Safety of Nis, Carnojevica 10 a, 18000 Nis, Yugoslavia

\begin{abstract}
In the modern engineering practice, the sound insulation of the partitions is the synthesis of the theory and of the experience acquired in the procedure of the field and of the laboratory measurement. The science and research public treat the sound insulation in the context of the emission and propagation of the acoustic energy in the media with the different acoustics impedance. In this paper, starting from the essence of physical concept of the intensity as the energy vector, the authors get down to defining the sound insulation, influential parameter and real partition oscillations.
\end{abstract}

\section{INTRODUCTION}

In the procedure of the coordinated planning, the modern requirements of the planning and the construction increasingly require, the analysis of the vibration and the acoustics processes as a function of programming the product quality of the wide spectrum functionality. The vibration and the acoustics protection impose the need for the oscillation process monitoring and for the oscillating structure emission definitio. Restricting the research area by the limit values of the audio frequency, the oscillating activity defined by the energy amount radiated space and time, unambiguously defines the quality value of the dynamic processes, by the expression for the sound power [1]:

$$
\mathrm{W}=\int_{\mathrm{S}} \overrightarrow{\mathrm{I}} \cdot \overrightarrow{\mathrm{n}} \cdot \mathrm{d} \mathrm{S}
$$

where the sound intensity is the time averaged product of the instantaneous pressure and the corresponding instantaneous particle oscillation velocity in the same position [2]:

$$
\overrightarrow{\mathrm{I}}=\overline{\mathrm{p} \cdot \overrightarrow{\mathrm{v}}}
$$

The sound pressure as the scalar quantity does not present any trouble in respect to a technical identification, whereas the particle oscillation velocity of the elastic medium, in spite of well-known theoretical relations, has not been verified by general applicable methods. However, the theoretical working out of the second Newton low and its application to the model of the defined fluid space in the expression of the Euler equation, have established the particle oscillation velocity definition by relating it to the pressure gradient.

In this way the organized methodical procedure enables that one of a series of problems of the modern engineering acoustics, the sound insulation partition, is treated in a way which closely defines the structure of the dynamic processes in the sound propagation and in the sound insulation. The reasons are 
contained in the fact that the developedmethodical procedures are the synthesis of the theoretical knowledge about the sound insulation and the experience acquired in the procedure of the field and the laboratory measurement. However, the influential factors of the real structure, above all the flanking transmission, other sound transmission paths as well as inhomogeneousness of the created structure from the practical point of view, and the partition oscillation are reason why the real idea about the sound insulation partition cannot be obtained.

\section{SOUND INSULATION IN FUNCTION OF SOUND INTENSITY}

The essence of the sound insulation partition is defined by the level difference between the sound energy incident on the partition $\mathrm{L}_{\mathrm{w}_{1}}$ and the sound energy transmitted in the receiving room $\mathrm{L}_{\mathrm{w}_{2}},[1]$ :

$$
\mathrm{R}=\mathrm{L}_{\mathrm{w}_{1}}-\mathrm{L}_{\mathrm{w}_{2}}
$$

Measurement of the transmission loss using the classical method in reality involves determination of sound power emitted in the receiving room making use of the reverberation time [3].

Starting from the fact that the sound intensity can be used for the sound power determination [4], the new methodical procedure is developed for the sound insulation determination of the partition. The sound insulation partition defined by the equation (2.1) invoves an analysis of the sound field configuration of the limited space both on the left and the right side of the partition. The sound power of the incident wave impinging on the partition is:

$$
\mathrm{W}_{1}=\sum_{\mathrm{i}=1}^{\mathrm{n}} \mathrm{I}_{\mathrm{li}} \cdot \Delta \mathrm{S}_{1 \mathrm{i}}
$$

where: $\quad I_{1 i} \quad$ - the averaged sound intensity of incident wave for the surface element $\Delta S_{1 i}$

$\Delta \mathrm{S}_{1 \mathrm{i}}$ - the element of the partition surface

$n \quad$ - number of the surface element $\Delta S_{1 i}$

Remaining in the sphere of the hypothetical model, with the homogeneous and the diffuse sound field in the source room, using statistical analysis, the sound power level of the incident wave is:

$$
\mathrm{L}_{\mathrm{w}_{1}}=\left(\overline{\mathrm{L}}_{\mathrm{p}}-6\right)+10 \cdot \log \mathrm{S}
$$

where $\overline{\mathrm{L}}_{\mathrm{p}}$ is the averaged sound pressure level in the source room.

We conclude that we have retained the same classical analytic method in the analysis of the sound field configuration at the source room, in order to make a functional relation between the sound insulation partition and the sound intensity emitted by the surface partition.

The sound power emitted by the partition in the receiving room is defined by the equation:

$$
\mathrm{W}_{2}=\sum_{\mathrm{j}=1}^{\mathrm{k}} \mathrm{I}_{2 \mathrm{j}} \cdot \Delta \mathrm{S}_{2 \mathrm{j}}
$$

where : $\quad I_{2 j} \quad$ - the averaged sound intensity emitted by the surface element $\Delta S_{1 j}$

$\Delta S_{1 j} \quad$ - the element of the partition surface $S$

$\mathrm{k} \quad$ - the number of surface elements.

When the differences in the emission of the elementary surfaces are small, the expression for the sound power level $\mathrm{L}_{\mathrm{w}_{2}}$ is :

$$
\mathrm{L}_{\mathrm{w}_{2}}=\overline{\mathrm{L}}_{\mathrm{I}_{2}}+10 \cdot \log \mathrm{S}
$$

where $\overline{\mathrm{L}}_{\mathrm{I}_{2}}$ is the averaged sound intensity level transmitted in the receiving room.

Replacing the equation (2.3) and (2.5) in equation (2.1), the sound insulation partition as function of the sound intensity is:

$$
\mathrm{R}=\left(\overline{\mathrm{L}}_{\mathrm{p}}-6\right)-\overline{\mathrm{L}}_{\mathrm{I}}
$$

For the inhomogeneous real partition that dominate in the engineering practice, the sound insulation of the surface element of the partition is: 


$$
R_{n}=\left(\bar{L}_{p}-6\right)-\bar{L}_{I_{n}}+10 \cdot \log \left(S / S_{n}\right)
$$

where $\bar{L}_{\text {In }}$ is the averaged sound intensity emitted by the surface element $S_{n}$.

Then the resulting sound insulation partition is:

$$
R^{\prime}=10 \cdot \log \sum_{i=1}^{n} 10^{\frac{L_{i}}{10}}
$$

\section{EXPERIMENTAL RESULTS}

The theoretical model verification has been carried out by an experiment at the real partition wall of the reinforced concrete, thick $15 \mathrm{~cm}$, with the area of $10.7 \mathrm{~m}^{2}$.The experiment plan is programmed with the function target, that enables the comparative analysis of the results obtained by classical method - the sound pressure level, in accordance to the standards ISO 140 [5], with the results of the sound intensity method. Performing of the experimental procedure has been realized by the measurement chain that is made of the following measurement equipment:

- Sound Source Type 4224 B\&K

- Building Acoustic Analyzer Type 4418 B\&K

- Dual Channel Signal Analyzer Type 2032 B\&K

- Sound Intensity Probe Type 3519 B\&K

The sound intensity identification has been carried out, for the partition wall in 40 discrete measurement points uniformly distributed at the surface of the party wall, by the sound intensity probe with a microphone spacing $\Delta \mathrm{r}=50 \mathrm{~mm}$ for the frequency range from $125 \mathrm{~Hz}$ to $500 \mathrm{~Hz}$, whereas $\Delta \mathrm{r}=12 \mathrm{~mm}$ was used for the frequency ranges from the $1000 \mathrm{~Hz}$ to $2000 \mathrm{~Hz}$. The sound intensity measurement emitted by flanking walls has been carried out by identical procedure by the scanning technical.

On the basis of the measurement value of the sound pressure in the source and receiving room, the sound intensity in the receiving room and the time reverberation of the source room, the sound insulation partitions have been calculated in accordance with both methods. The obtained results are shown on the Fig. 1

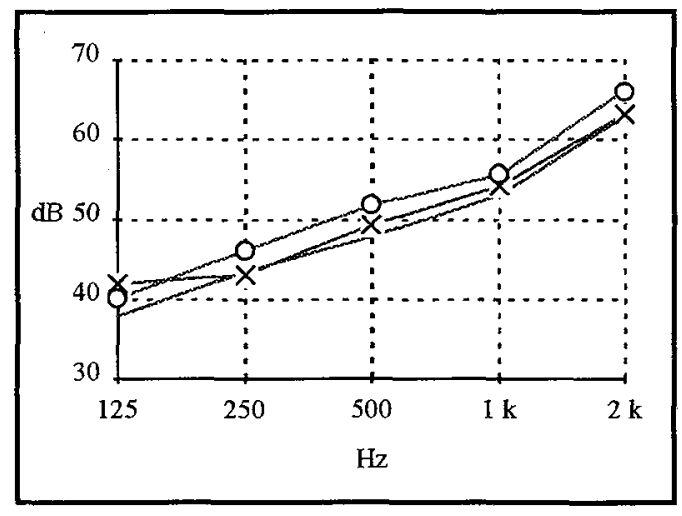

Fig. 1 Sound insulation: $\mathrm{x}-\mathrm{x}$ Classical method; Intensity method: - total, o-o party wall
The segments of the results obtained in the experimental analysis, show that the contribution of the flanking transmission in expressing of the sound insulation is very important. The results show that the flanking transmission with its negative influence reduces the insulation index, approximately by the order of magnitude of $3 \mathrm{~dB}$. The influence of the flanking transmission at the lower frequencies to 500 $\mathrm{Hz}$ is almost negligible, whereas at the higher frequency above $500 \mathrm{~Hz}$ it is very important, especially at $2 \mathrm{kHz}$. Taking into consideration the object structure and the building manner at the examination model, as well as the results obtained by the experimental analysis we find that the intensity definition, obtained by the determination method the sound insulation, is of special importance for the flanking transmission identification in the investigation procedure of the light mounting constructions.

The investigation carried out in order to include the sound intensity into the measurement procedure of the sound insulation partition discovered the new approaches in the examination of the oscillation processes phenomenon, as contour maps and 3-D plots of the sound intensity distribution. Examples of contour maps and 3-D plots of the examination partition are shown on Fig. 2. 


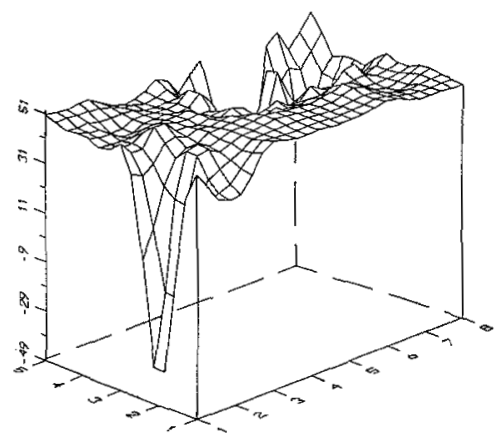

$500 \mathrm{~Hz}$
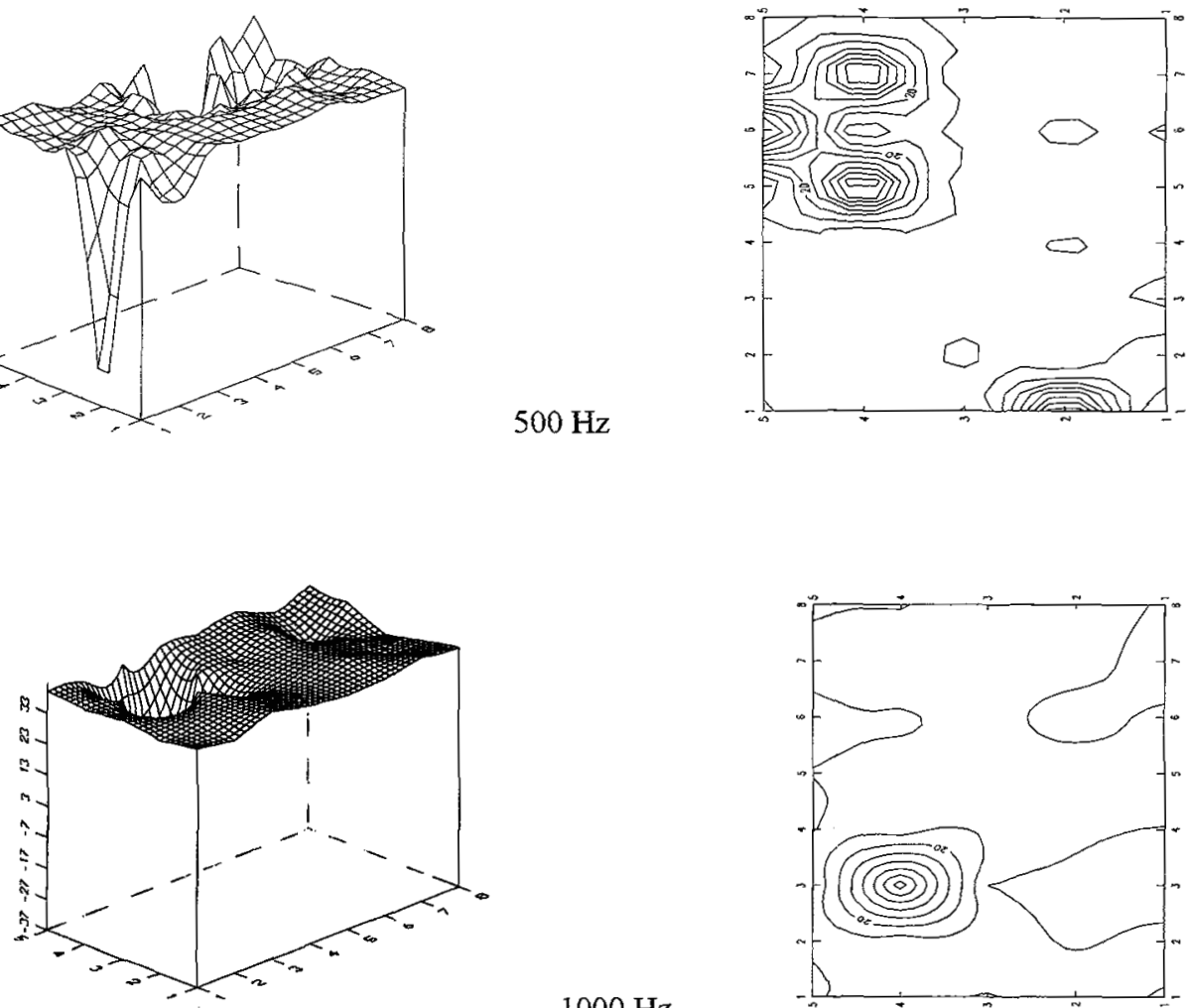

$1000 \mathrm{~Hz}$

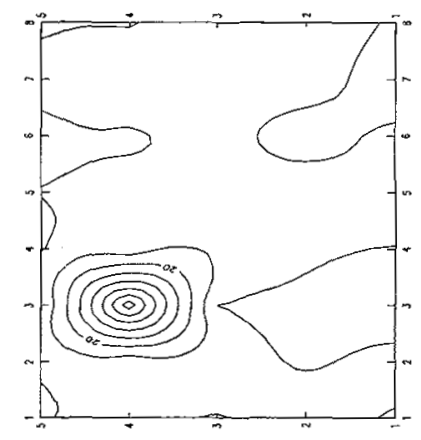

Fig. 2 Examples contour maps and 3-D plots of the examination partition

\section{CONCLUSION}

The sound intensity applied to the problem of the sound insulation partition in the domain of the building construction and its significance for the technical and technological system development imposes the following conclusions:

- The sound intensity method is the subtle method that should be used in the development procedure of the new modern, especially light partitions.

- The sound intensity method should be used combined with the methods of the oscillating process structure analysis, because the sound emission is in direct connection with the oscillating process.

- The results obtained in the experimental procedure are useful in multiple ways opening in the diagnostic sense the content of the sound insulation through the prism of the influential flanking transmission of the other construction elements.

- The sound intensity method, clearly and unambiguously, project the new direction in the examination of the sound transmission energy process and the partition behavior in acoustically active media.

\section{REFERENCES}

[1] Beranek L., Noise and Vibration Control, McGraW-Hill, New York, 1971

[2] Gade S., Sound intensity, B\&K Technical Review, 1982 No 3,4

[3] Cvetkovic D., Prascevic M., Sound Insulation Determination by Intensity method, XIV Yugoslav \& II International Conference "Noise and Vibration in Living and Working Environment", Nis, 1993

[4] Cvetkovic D., Uzunovic R., Prascevic M., Comparative analysis of applicable method of determination of sound power, 14 ICA, Beijing, 1992

[5] ISO 140, Measurement of Sound Insulation in Building and of Buildings Elements 